\title{
Apron Conflict Prediction and Avoidance for Aircraft in Large Airport
}

\author{
Zhu Xinping $^{1+}$, Xu Haiyao ${ }^{1}$ \\ ${ }^{1}$ College of Air Traffic Management, Civil Aviation Flight University of China, Sichuan 618307, China
}

\begin{abstract}
In order to ensure the safe operation of apron, it is necessary to implement apron control system integrated with advanced movement conflict control algorithm. Six classes of apron conflicts that may occur in apron operation are summarized, and the corresponding characteristics are analyzed in detail. The approach for constructing static network graph (SNG) based on virtual control node, and dynamic network graph (DNG) for aircraft apron movement are provided with the prior information on taxi routes, respectively. The concept of apron movement cycle, cycle chain, and shareable unidirectional route in DNG are proposed, and the apron conflict prediction and avoidance algorithm was proposed for apron conflict type 1-4. Lastly, the effectiveness of the proposed algorithm was validated through numerical study and simulation experiment.
\end{abstract}

Keywords: airport, apron, conflict prediction, conflict avoidance.

\section{Introduction}

The apron is a defined area designated for parking of aircraft and is usually adjacent to the terminal building. With the increase of flight demand, apron operation is becoming much more complicated, especially for large airport. Combined with a variety of ground support vehicles or people in apron, the apron has become one of the most complex areas in airport. Normally, the apron operation is controlled by apron control towers implemented in some large airports in China mainland, or air traffic control towers. In current manual operations, it is difficult for controllers to consider or solve apron conflicts in an exact and efficient manner, due to uncertainties and the increasing traffic demand. From this point of view, the development of apron control automation system integrating advanced apron conflict control algorithm has become critical to a successful apron operation. In this paper, given knowledge of aircraft apron surveillance data and taxi routes, the aircraft apron conflict control algorithm is investigated.

When an aircraft arrives at an airport, it manoeuvres from the runway to the apron area through taxiway system. The apron traffic system contains aircraft parking stands (or gates), apron taxiways, apron taxi lanes, vehicle roads. The parking stands are assigned for parking of aircrafts, where aircrafts receive the turnaround service, like unload and load, passengers or baggage, etc. The apron taxiways are usually located on the periphery of an apron area. The apron taxi lanes are used by aircraft taxi into the stand or taxi out. The vehicle roads are used by ground support vehicles, like baggage car or fuelling vehicle. In being routed to apron stands, aircrafts may encounter other taxiing aircrafts, or may have to wait for its assigned stand to be vacated by another departure aircraft. Also, aircrafts may be in conflict with other ground vehicles.

In order to reduce the apron conflict probability, the colour pushback procedure is adopted by Hong Kong and Singapore airport authority. Other previous researches concerning the apron conflict control are concentrated with how to simulate the aircraft movement in apron. Cheng models the aircraft pushback conflict using a spatial-time network-based simulation method [1]. Liu reports a colored Petri-net model for

\footnotetext{
+ Corresponding author. Tel.: + 086-13419037831;

E-mail address: zhu408@163.com.
} 
aircraft pushback conflict control, but it was only a simulation model for conflict prediction without avoidance algorithm [2]. Also, several other simulation models have been proposed. Pitfield proposes a Monte-Carlo simulation model to demonstrate the conflict between the towed aircraft in need of maintenance and regular arriving and departing aircraft [3]. Gao provides the concept of shared stop points and formulates the stop points setting problem as a mix-integer programming model, in order to avoid the aircraft apron conflict [4]. On the other hand, Dieker describes a mathematical model for the prediction of aircraft pushback trajectories under various geometric constellations in order to avoid the apron conflict [5]. Gao presents a knowledge base model for the simulation and avoidance of aircraft conflicts in apron [6]. For all of the previous research, none of them has studied how to solve the apron conflicts for the overall apron, and they only focus on control of conflicts occurring near the apron stands.

Section 2 of this paper summarizes the characteristics of aircraft apron conflicts. Base on that, section 3 describes the apron traffic system modelling method and shows the dynamic network graph describing the aircraft movement process in apron. Section 4 provides an apron conflict prediction and avoidance algorithm for aircraft. A numerical study and simulation experiment are demonstrated in section 5. Section 6 summarizes the main findings.

\section{Aircraft Conflicts Analysis in Apron}

The apron conflict is defined as the situation that surface object (aircraft or vehicle) is occupying or attempt to occupy the same unsharable space, typically a junction, a taxiway intersection, or a pushback stop point, leading the surface separation standards to be violated. Thus, for the safety of aircraft operations, there are two general methods to determine whether an apron conflict exists or not: (a) a minimum separation space between aircraft in apron; and (b) only one aircraft may occupy a conflict point or cross point at any one time. According to the spatial and time characteristics, the apron conflicts can be categorized into static conflict and dynamic conflict [7]. The latter can be fatherly categorized into pushback congestion and taxing congestion [8]. In this paper, the apron conflicts can be classified into following six types:

(1) type 1: the departing aircrafts in two adjacent or non-adjacent stands are pushed out to the same pushback (PB) stop point, as shown in Fig.1, which is the situation that aircrafts are pushed out to the same $\mathrm{PB}$ point at the same time, or the two different pushback times are very close.

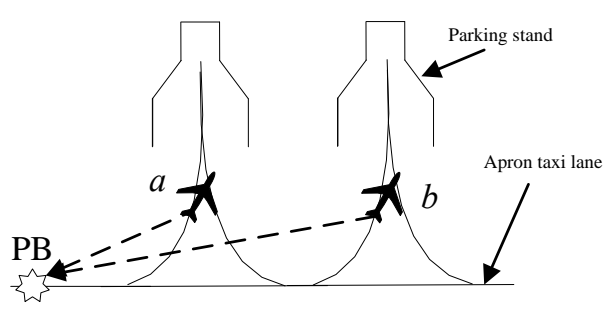

Fig. 1: Aircraft conflict in apron-type1

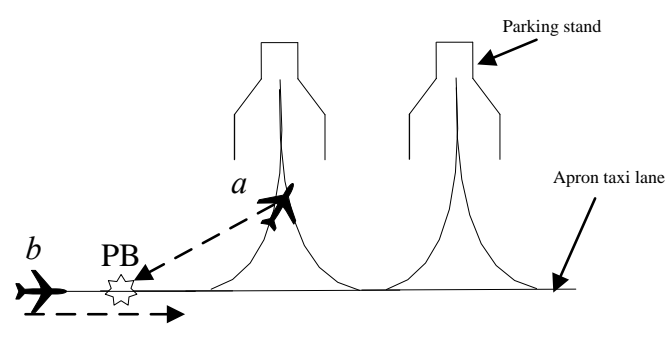

Fig. 2: Aircraft conflict in apron-type 2

(2) type 2: conflict between the taxiing aircraft on apron taxi lane and aircraft in pushback process, as shown in Fig.2, which is the situation that aircraft $b$ is taxiing on taxi lane, while the aircraft $a$ is pushed to the PB point resulting into the apron taxi lane is congested.

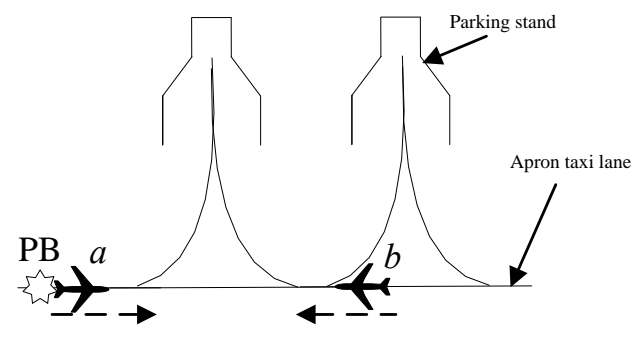

Fig. 3: Aircraft conflict in apron-type 3

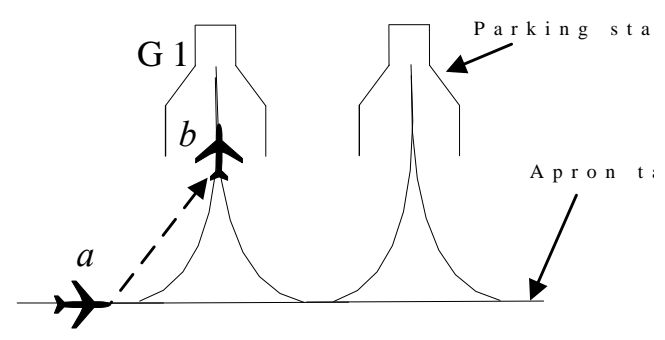

Fig. 4: Aircraft conflict in apron-type 4 
(3) type 3: head-on conflict between aircrafts taxiing on the apron taxi lane, as shown in Fig.3, which is the situation that aircraft $a$ is taxiing in one direction, while the aircraft $b$ is taxiing in the opposite direction on the same apron taxi lane.

(4) type 4: the conflict between aircraft that is about to enter one stand and the aircraft that is occupying the stand, as shown in Fig.4, which is the situation that, aircraft $a$ is taxiing on taxi lane and about to enter stand G1, and at the same time there is aircraft $b$ occupying the same stand G1.

(5) type 5: when aircrafts in two adjacent stands request simultaneous push back, there is a potential collision conflict between these two aircrafts, as shown in Fig.5, the wingtips of aircrafts may collide each other in the pushback process. It should be noted that this situation is equivalent to the situation that aircraft $a$ is in the process of push-out, while aircraft $b$ is taxing into the adjacent stand.

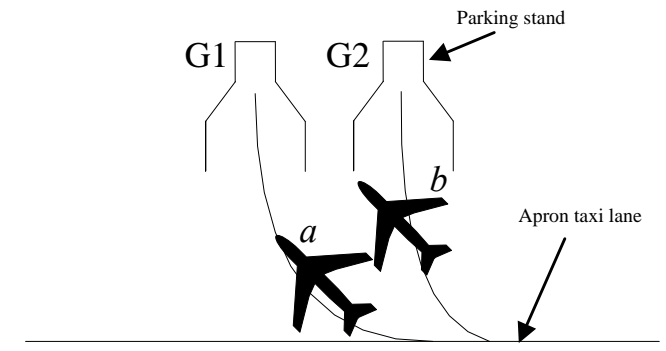

Fig. 5: Aircraft conflict in apron-type 5

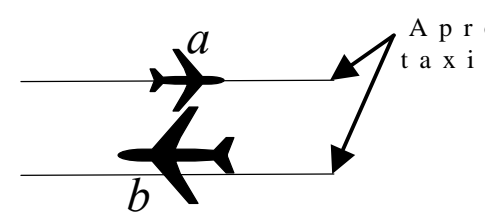

Fig. 6: Aircraft conflict in apron-type 5

(6) type 6: the collision conflict which is caused by the taxi route deviation of aircraft taxiing in the apron taxi lane, as shown in Fig.6, aircraft $a$ and $b$ is taxiing on the apron taxiway, there is a potential collision conflict between aircrafts resulting from the taxi route deviation of aircraft $b$.

\section{Apron Traffic System Modelling}

\subsection{Static network graph for apron traffic system base on virtual control node}

The apron traffic system contains typical units, like parking stands, apron taxi lanes, apron taxiways, and so on. These units can be divided into operation zones, according to the apron physical layout, as shown in Fig.7(a). The cross point between the borders of two neighbouring zones is named as virtual control node.

The apron traffic system can be represented by a static network graph (SNG) based on virtual control node, which is defined as direction graph $G=(V, E)$, whose node set $V=V_{1} \cup V_{2}$ is the set of virtual control nodes ( $\mathrm{VCN})$, and $V_{1}$ is the set of $\mathrm{VCN}$ on the apron taxi lane, $V_{2}$ is the set of $\mathrm{VCN}$ on apron taxiway. The nodes are connected by arcs that are used to describe the neighbour relationship between two corresponding zones. $E$ is the directional arcs sets. For example, a directional arc $e_{i j} \in E$ is in correspondence with the neighbour relation from node $v_{i} \in V$ to node $v_{j} \in V$.

For apron traffic system in Fig.7(a), the corresponding SNG based on virtual control node is demonstrated as Fig.7(b). The node $v_{i}(i=1,2,3, \ldots)$ are the virtual control nodes.

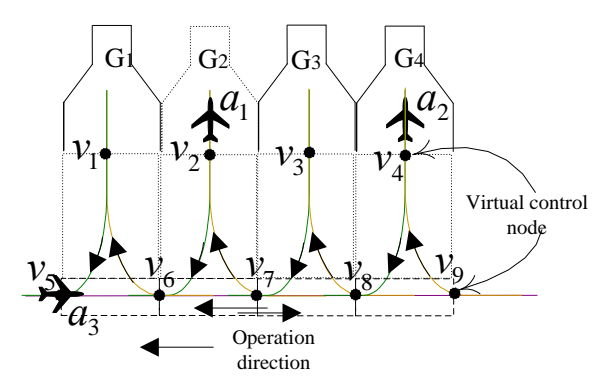

(a)Part of apron traffic system

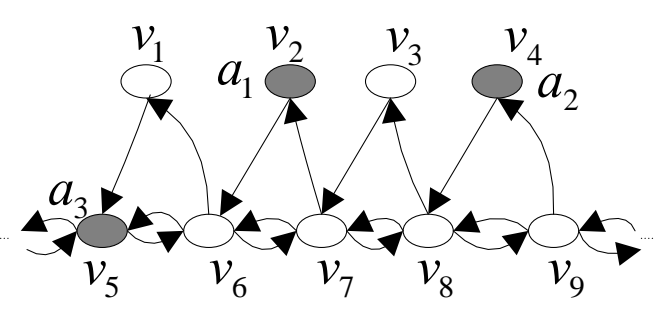

(b) static network graph for apron traffic system

Fig. 7: part of apron traffic system and its corresponding network graph

\subsection{Dynamic network graph for aircraft movement in apron}

Normally, there are various different taxiing routs for both arrival and departure aircrafts. For SNG shown in Fig.7, assume that the residual taxiing route of aircraft $a_{1}$ (currently occupy $v_{2}$ ) includes node 
$v_{6}, v_{7}, v_{8}, v_{9}, \ldots$; the residual taxiing route of aircraft $a_{2}$ (currently occupy $v_{4}$ ) includes node $v_{8}, v_{7}, v_{6}, \ldots$; the residual taxiing route of aircraft $a_{3}$ (currently occupy $v_{5}$ ) includes node $v_{6}, v_{7}, v_{8}, v_{9}, \ldots$.

The dynamic network graph (DNG) for aircraft movement in apron is defined as $G_{\mathrm{r}}=\left(V_{\mathrm{r}}, E_{\mathrm{r}}\right)$. The node set $V_{\mathrm{r}}=\operatorname{rr}\left(a_{1}\right) \bigcup \operatorname{rr}\left(a_{2}\right) \cup \ldots \cup \operatorname{rr}\left(a_{n}\right)$ is compose of the residual nodes on aircraft taxiing routes, $n$ is the number of aircraft in apron. According to the aircraft taxiing routes, if the node $v_{i} \in V_{r}$ is the immediate predecessor of node $v_{i} \in V_{r}$, then there exists an arc $\mathrm{e}_{i j}$ from $v_{i}$ to $v_{i}$, which is one of the elements in set $E_{\mathrm{r}}$. The state of DNG for aircraft movement is represented by the nodes set and directional arcs set. According to the definition of DNG, the node set $V_{\mathrm{r}}$ shall be updated dynamically by the residual taxiing route of aircrafts. Thus, the state of DNG can be updated according to the following rules:

Rule 1: when the aircraft is approved to taxi from one control virtual node (called preceding node) to another one (called immediate succeeding node), and the movement is already in process, the immediate succeeding node in DNG will be marked gradually, as shown in Fig.8(b);

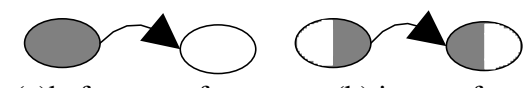

(a)before transfer (b) in transfer

Fig. 8: Mark process demonstration for node in dynamic network graph

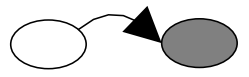

(c) after transfer

Rule 2: when the aircraft arrive at one virtual control node, the corresponding node in DNG is marked totally, as shown in Fig.8(c); at the same time, the preceding node $v_{5}$ is deleted from the dynamic network graph, as shown in Fig.9;

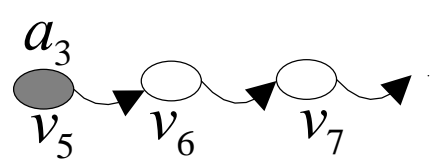

(a)before transfer

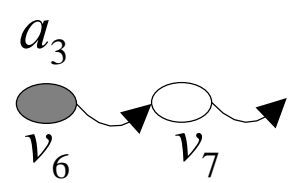

(b) after transfer

Fig. 9: Update process of aircraft dynamic network graph

For surveillance data update rate and the physical size of aircraft, it is difficult for apron control system to accurately determine when one aircraft leave or enter one apron operation zone, but it is feasible to determine whether one aircraft occupy one virtual control node, or not, by comparing the coordination of node with that of aircraft physical centre as follows: assume the trajectory of aircraft $a_{i}$ can be described by point set $T r_{i}=\left\{\left(x_{i 0}, y_{i 0}, z_{i 0}, S_{i 0}\right),\left(x_{i 1}, y_{i 1}, z_{i 1}, S_{i 1}\right), \ldots\right\}$, for the coordination of one virtual control node $v_{i}=\left(x_{i}, y_{i}, z_{i}\right)$, if $x_{i}=x_{i k}(k=0,1,2, \ldots)$ and $y_{i}=y_{i k}(k=0,1,2, \ldots)$, then, aircraft $a_{i}$ is occupying the corresponding virtual control node.

For the DNG of aircraft apron movement, if there exist node $v_{i}$ and $v_{j}$ occupied by the same aircraft successively, then the $v_{j}$ is reachable by $v_{i}$; meanwhile, if $v_{i}$ is reachable by $v_{j}$, these two nodes are reachable mutually.

For the DNG $G_{\mathrm{r}}$, if there exist two adjacent nodes, $v_{i}$ and $v_{j}$, are mutually reachable within taxi routes of two aircrafts, then the corresponding routes forms cycle between $v_{i}$ and $v_{j}$. Further, the cycle chain in DGN is defined as follows: if each two adjacent nodes, $v_{i}$ and $v_{j}, v_{j}$ and $v_{k}, \ldots, v_{m}$ and $v_{n}$, forms cycle, the above nodes forms cycle chain.

Thus, for SNG in Fig.7, according to the taxiing routes of aircraft $a_{1}, a_{2}, a_{3}$, node $v_{6}$ and $v_{7}, v_{7}$ and $v_{8}$, are reachable mutually, there exists cycle chain, as shown in Fig.10.

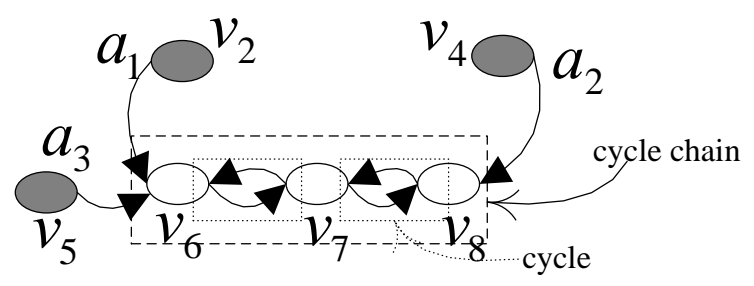

Fig. 10: Cycle and cycle chain derived from SNG in Fig.7 
If there are two taxiing routes $\operatorname{rr}\left(a_{l}\right)$ and $\operatorname{rr}\left(a_{s}\right)$ meet the following conditions:

- $\operatorname{rr}\left(a_{l}\right) \cap \operatorname{rr}\left(a_{s}\right)=\left\{v_{i}, v_{j}, \ldots, v_{k}\right\}$;

- there is no cycle or cycle chains for routes in node set $\left\{v_{i}, v_{j}, \ldots, v_{k}\right\}$;

Then, the common part of taxiing routes, that is node set $\left\{v_{i}, v_{j}, \ldots, v_{k}\right\}$, is call shareable unidirectional route. For DNG shown in Fig.10, the common part $\left\{v_{6}, v_{7}, v_{8}, v_{9}, \ldots\right\}$ of taxiing routes $\operatorname{rr}\left(a_{1}\right)$ and $\operatorname{rr}\left(a_{3}\right)$ is shareable unidirectional route, as shown in Fig.11.

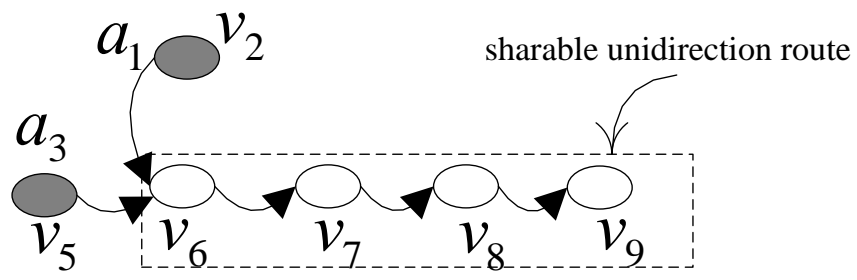

Fig. 11: Shareable unidirectional route derived from SNG in Fig.7

\section{Apron Conflict Prediction and Avoidance Algorithm for Aircraft}

For aircraft apron conflict type 1-4, aircraft collision will not occurs immediately, we provide the conflict prediction and avoidance algorithm to resolve these four conflict categories in this paper.

\subsection{Apron conflict prediction algorithm}

Based on the DNG of aircraft apron movement, the apron conflict prediction algorithm is provided with basic idea determining the cycle, cycle chain and shareable unidirectional route based on the dynamic state of DNG. The performance of proposed algorithm relies on the update rate of apron surveillance data. And it periodically predicts the apron conflict by following steps:

Step 1: for aircraft $a_{i}$, extract the currently occupied virtual control node from the DNG based on the surveillance data, and also the immediate succeeding node $v_{j}$ that will be occupied according to the taxi route $\operatorname{rr}\left(a_{i}\right)$; at the same time, node $v_{j}$ is added to set $\Pi_{i}$;

Step2: if the control node $v_{j}$ is occupied, then the conclusion "the movement is congested as result of a potential conflict" is drawn; or else, step3;

Step3: fatherly extract the immediate succeeding control node of $v_{j}$ in taxi route $\operatorname{rr}\left(a_{i}\right)$, for example $v_{k}$, and add it into the set $\Pi_{i}$; if the node $v_{k}$ is not occupied, then the conclusion "the movement can be execute without a potential conflict" is drawn; or else, step4

Step 4: for aircraft $a_{m}$ occupying the control node $v_{k}$, extract the node from taxi route $\operatorname{rr}\left(a_{m}\right)$ and add them into node set $\Pi_{m}$; step 5;

Step 5: for node set $\Pi_{i}$ and $\Pi_{m}$, if $\Pi_{i} \subseteq \Pi_{m}$ and the nodes in these two sets form cycle or cycle chain, then the conclusion "movement is congested for potential apron conflict type 3 or 4 " is drawn; if $\Pi_{i} \subseteq \Pi_{m}$ and the nodes in these two sets form shareable unidirectional route, then the conclusion "movement is congested for potential conflict type 1 or 2 " is drawn.

\subsection{Apron conflict avoidance strategies}

When an apron conflict between two aircrafts is predicted, it is necessary to decide which aircraft will prevail. Basically, there are two methods to avoid apron conflict. One is the modification of taxi route which guides aircraft taxi in a new route; the other is the publication of control command which delay the aircraft waiting in some reasonable point. Basically, the aircraft taxiing route in apron is relatively sample for the space restriction, thus, the latter waiting strategy is adopted and investigated in this paper.

Strategy 1: if there are several types of potential apron conflicts occurs or will occur near one stand, for aircraft occupying stand in the conflict, we delay it waiting on the stand;

Strategy 2: if there is only one potential apron conflict in somewhere, we instruct aircraft hold on one virtual node and the movement of departure aircraft shall be provided priority; 
Strategy 3: if there is a potential pushback conflict in somewhere, the movement priority shall be given to the one which closes cabin door earlier.

\section{Numerical Study and Simulation}

Taking the situation in Fig.7 as an example, the proposed apron conflict prediction and avoidance algorithm is evaluated in a numerical study. Assume the residual taxi route of aircraft $a_{1}, a_{2}, a_{3}$ are $r r\left(a_{1}\right)=\left(v_{6}, v_{7}, v_{8}, v_{9}, \ldots\right), r r\left(a_{2}\right)=\left(v_{8}, v_{7}, v_{6}, v_{5}, \ldots\right), \operatorname{rr}\left(a_{3}\right)=\left(v_{6}, v_{7}, v_{8}, v_{9}, \ldots\right)$, respectively. Thus, the dynamic network graph (DNG) for aircraft apron movement can be established using these taxiing routes, as shown in Fig.12.

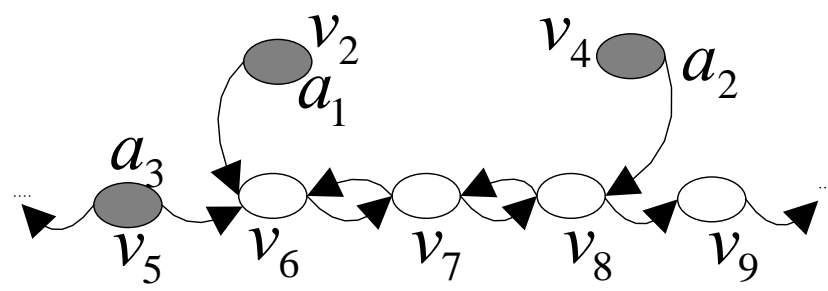

Fig. 12: dynamic network graph (DNG) derived from SNG in Fig.7

According to the definitions of cycle, cycle chains, shareable unidirectional route, the taxiing routes of aircraft $a_{1}$ and $a_{2}$ in node set $\left\{v_{6}, v_{7}, v_{8}\right\}$ forms cycle chains. Thus, the aircraft $a_{1}$ and $a_{2}$ is in conflict with each other.

Further, the taxi routs of aircraft $a_{1}$ and $a_{3}$ in node set $\left\{v_{6}, v_{7}, v_{8}, v_{9}\right\}$ forms shareable unidirectional route. Thus, there exists potential apron conflict between $a_{1}$ and $a_{3}$. In order to avoid the above apron conflicts, aircraft $a_{1}$ and $a_{2}$ are delayed waiting in the stand according the strategy 1 , while the movement of aircraft $a_{3}$ could be approved. And then, for the conflict between aircraft $a_{1}$ and $a_{2}$, it can be avoided through the use of strategy 3 .

Further, in order to evaluate the effectiveness of the algorithm proposed in this paper, a simulation platform integrating the apron conflict control algorithm is developed. For the case in Fig.13(a), the conflict on the apron taxi lane is predicted between the arrival aircraft AR001 and departure aircraft DEP003 by the platform. And then, the departure aircraft DEP003 is delayed to holding on one control node, and the arrival aircraft ARR001 is instructed to taxi into the designated stand. After the aircraft ARR001 taxi into the stand, the apron taxi lane is clear, and then the departure aircraft DEP003 is instructed to taxi.

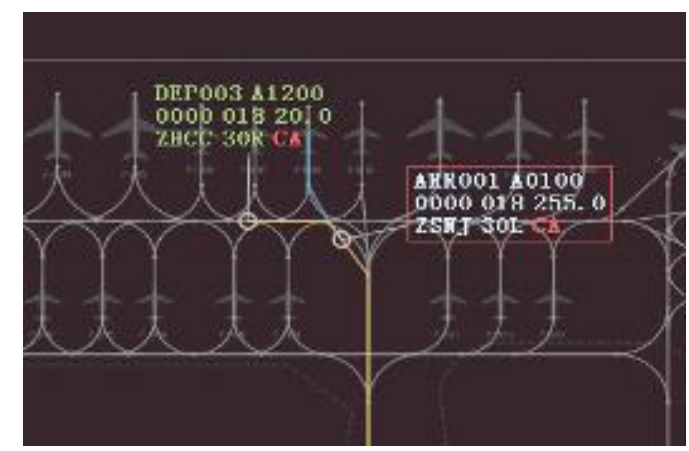

(a)The prediction of apron conflict in simulation

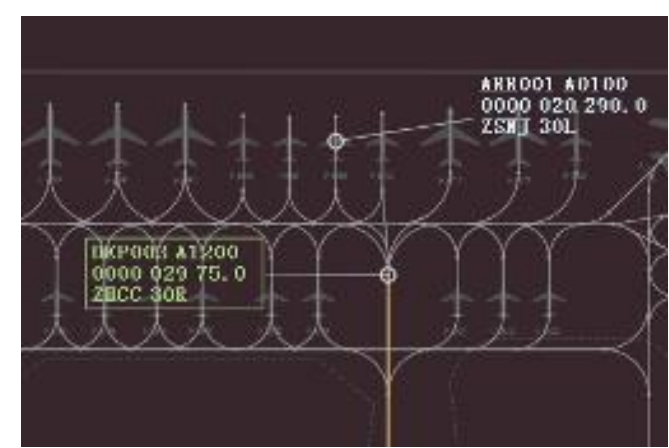

(b) The avoidance of apron conflict in simulation

Fig. 13: Prediction and avoidance of aircraft apron conflict in simulation

\section{Conclusion}

Airport apron is a complicated and essential part for a successful airport. In order to improve the safety and efficiency of apron operation, it is possible and necessary to develop and use automatic apron control system. For the apron conflict control, the conflict prediction and avoidance algorithm are proposed based on the network graph. As a summary, the principal contributions of this paper are as follows:

- Six classes of apron conflicts that may occur in apron operation are summarized, and the corresponding characteristics are analyzed in detail. The approach for constructing static network 
graph (SNG) based on virtual control node, and dynamic network graph (DNG) for aircraft apron movement are provided, respectively.

- The concept of apron movement cycle, cycle chain, and shareable unidirectional route in DNG are proposed. Most importantly, for apron conflict type 1-4, the corresponding apron conflict prediction and avoidance algorithm is put forward. By the results obtained from the numerical study and simulation experiment, the proposed algorithm is feasible and effective.

It should be noted that the proposed algorithms can only tackle the apron conflict type 1-4. For the apron conflict type 5-6, as the aircraft may collide with each other, we need to provide the apron conflict detection and resolution algorithm, which take the apron operation uncertainty into consideration, and this leaves as a further research in future.

\section{Acknowledgements}

The authors would like to thank the anonymous reviewers whose comments have helped us to improve the presentation of the paper. This research is supported by National Key R\&D Program of China (Grant No.2018YFC0809500), Fund for Young Scholars of CAFUC (Q2015-079), and Joint Funds of the National Science Foundation of China and the Civil Aviation Administration (Grant No. U1733105)

\section{References}

[1] CHENG Y. Solving push-out conflicts in apron taxiways of airports by a network-based simulation. Computers Industrial Engineering, 1998, 34(2): 351-369.

[2] LIU Changyou, ZHANG Li. Modeling and Simulation on Flight Push-out Conflicts Based on Colored Petri Net. Porc. of the 29th Chinese Control Conference, Beijing, China, 2010:5447-5452.

[3] Pitfield, D, Brooke A, Jerrard E A. A Monte-Carlo simulation of potentially conflicting ground movements at a new international airport. Journal of Air Transport Management, 1998, 4(1): 3-9.

[4] GAO Qiang, TANG Xiawei, ZHU Jinfu. Design Optimization for the Shared Stop Points at Aircraft Parking Area. Computer and Communications, 2009, 27(6):156-160.

[5] Dieke-Meier, F. Modeling aircraft pushback trajectories for safe operation. Proc. Of the ATACCS 2012, Naples, 2013:76-84.

[6] Gao Wei, Zhang jia. Rules-based Study of Conflicts Detection and Resolution in Ramps. Proc. Of the third international conference on intelligent system design and engineering application, 2013: 1238-1241.

[7] FENG Cheng. Research on optimization techniques of airport surface operation and capacity evaluation. Thesis, Nanjing, Nanjing Aeronautics and Astronautics, 2013

[8] WANG Peng Tao. Research on Modeling of Apron Push-back Simulation. Thesis, Tianjin: Civil Aviation University of China, 2015. 